\title{
Calcinosis Cutis Confined to the Dermis after Intravenous Administration of a Calcium Preparation: A Case Report and Review of the Japanese Literature
}

\author{
Soko Watanabe ${ }^{a}$ Takeaki Shioda $^{a} \quad K^{2}$ Kobayashi ${ }^{a} \quad$ Sumiko Ishizaki ${ }^{a}$ \\ Fumio Ito $^{\text {b }}$ Mariko Fujibayashic $^{c}$ Masaru Tanaka $^{a}$ \\ Departments of ${ }^{\mathrm{a}}$ Dermatology, ${ }^{\mathrm{b}}$ Urology and ${ }^{\mathrm{C}}$ Pathology, Tokyo Women's Medical \\ University Medical Center East, Tokyo, Japan
}

\section{Key Words}

Iatrogenic calcinosis · Calcium chloride

\begin{abstract}
A 61-year-old female received intravenous injection of calcium chloride after common iliac artery bypass surgery. A red flare appeared at the site of the intravenous infusion on the left forearm and gradually progressed to induration. Seven weeks later, she was referred to the Department of Dermatology for management. Physical examination showed an indurated plaque measuring $13 \times 65 \mathrm{~mm}$ in size, with linearly distributed ulcers covered by yellowishwhite substance, surrounded by reddish skin. Laboratory tests showed no significant abnormalities including serum calcium, phosphate and thyroid hormones. Cultures were negative for microorganisms. Histopathological examination showed calcium deposition confined to the dermis. The lesion healed spontaneously within 2 months with scar formation. A review of the Japanese literature showed confinement of calcium deposits to the dermis in most of the reported cases. We speculate that the pathomechanism of dermal calcinosis includes needle-induced tissue injury with capillary destruction, leading to release of excess calcium between collagen fibers, and its binding to phosphate in the dermis and deposition as calcium phosphate crystals.

(C) 2014 S. Karger AG, Basel
\end{abstract}

Soko Watanabe MD

Department of Dermatology

Tokyo Women's Medical University Medical Center East

2-1-10 Nishi-Ogu, Arakawa-ku, Tokyo 116-8567 (Japan)

E-Mailsoko1031@yahoo.co.jp 
Watanabe et al.: Calcinosis Cutis Confined to the Dermis after Intravenous Administration of a Calcium Preparation

\section{Introduction}

Calcinosis cutis is subdivided into four types, namely metastatic, dystrophic, idiopathic and subepidermal calcinosis [1]. According to this classification, the present case would be classified as dystrophic calcinosis following local tissue injury. Calcinosis associated with the injection of a calcium chloride preparation was recently described as iatrogenic calcinosis [2]. Recently, we encountered a similar case, and discuss here the relationship between the route of administration and the site of calcium deposition.

\section{Case Report}

A 61-year-old Japanese woman presented with induration on the left forearm. The family history was not remarkable. The medical history included bladder cancer diagnosed 10 weeks earlier, which was resected surgically. Inadvertently, the left iliac artery was occluded during the operation. This was treated intraoperatively by common iliac artery bypass and intravenous infusion of $2 \%$ calcium chloride into the arm vein to induce vasoconstriction. Postoperatively, no extravasation of the injected preparation was noted on the arm, but a red flare appeared around the area of administration. The red flare gradually led to induration and ulcer formation. The patient was referred to the Department of Dermatology at postoperative week 7 for further management.

Physical examination showed an indurated plaque of $13 \times 65 \mathrm{~mm}$ with linearly distributed ulcers covered by yellowish-white material, and the entire lesion was surrounded by reddish skin (fig. 1). Laboratory data showed BUN $25.2 \mathrm{mg} / \mathrm{dl}$ (normal: 7.0-22.0), serum creatinine $0.97 \mathrm{mg} / \mathrm{dl}$ (normal: $0.3-0.8$ ), serum calcium $9.3 \mathrm{mg} / \mathrm{dl}$ (normal: 8.0-10.5), serum phosphate $4.4 \mathrm{mg} / \mathrm{dl}$ (normal: 4.0-6.0), and high sensitivity-parathyroid hormone 460 $\mathrm{pg} / \mathrm{ml}$ (normal: 160-520). Cultures were negative for acid-fast bacilli and fungi.

Two skin biopsy samples were obtained from the left forearm. The histopathological findings were similar in the two specimens and included deposition of basophilic amorphous substance in the upper and middle dermis (fig. 2a), but not in the subcutis. The amorphous material was eliminated transepithelially, with partial defect of the epidermis and substitution with crust. There was granulomatous infiltration surrounding the amorphous material with underlying collagen accumulation. Histiocytic infiltrates intermingled with lymphocytes and giant cells among the collagen fibers (fig. 2b). The amorphous substance stained black with von Kossa staining (fig. 2c). Based on the above clinical and histopathological findings, the final diagnosis was calcinosis cutis. The whitish chalky substance disappeared gradually within 1 month, together with healing of the ulcers within 2 months, with scar formation (fig. 3).

\section{Discussion}

A search of the Japanese literature published between 1990 and 2012 identified 18 cases of calcinosis cutis after administration of calcium preparations (table 1) [3-15]. The data included in table 1 are sorted according to the presence/absence of extravasation and the depth of the lesion. In the 3 biopsied cases out of 7 without extravasation, the deposition was confined to the dermis [9-15]. In comparison, biopsies were obtained from 6 out of 10 cases with extravasation and the deposition was confined to the dermis in 4 out of 6 cases, 
Watanabe et al.: Calcinosis Cutis Confined to the Dermis after Intravenous Administration of a Calcium Preparation

although the extravasation should occur in the subcutis. Therefore, direct deposition is not the reason of calcinosis in the dermis.

Several recent case reports described iatrogenic calcinosis cutis without obvious extravasation after administration of calcium preparations. Usui et al. [8] argued that calcinosis cutis represents intravascular or vascular wall deposition, which is triggered by endothelial failure or obstruction by catheter tip misplacement, in the presence of local hypercalcemia near the catheter. In their opinion, it is a secondary extravasation due to vascular occlusion. However, the lesion in the 3 cases without extravasation, including our case, was confined to the dermis, i.e., lack of involvement of subcutaneous vessels and no use of catheters. Since there is no discussion of this feature, we hypothesize that the pathomechanism of calcinosis cutis is as follows: introduction of the needle causes tissue injury, which causes capillary disruption in the dermis (fig. 4b), leading to a transient increase in calcium concentration in the extracellular matrix between collagen fibers, with subsequent binding of calcium to phosphate in the dermis (fig. 4c) and deposition of calcium phosphate crystals in the dermis. Further studies are needed to confirm the above mechanism of calcium deposition.

\section{References}

1 Maize JC, Maize JC Jr, Metcalf J: Metabolic diseases of the skin; in Elder DE, Elenitsas R, Johnson BL Jr, Murphy GF, Xu G (eds): Lever's histopathology of the skin, ed 10,

2 Hanada K: Calcinosis cutis (in Japanese); in Tamaoki K, Iiduka H, Shimizu H, Tomita Y, Miyachi Y, Hashimoto K, Furuya M (eds): Saishin Hifuka Taikei, Nakayama Shoten. Tokyo 2003;10:103-105.

3 Sakai H, Matsuo S, Iiduka H, Tsuchida A: A case of calcinosis associated with intravenous injection of calcium gluconate (in Japanese). Rinsho Hifuka 1995;49:75-77.

4 Baba H, Hamatani S, Onoe T, Hori K, Nagai Y, Koda H, Nakagawa H: A case of calcinosis cutis induced by intravenous injection of calcium gluconate (in Japanese). Rinsho Hifuka 2008;62:891-893.

5 Seike T, Sugino H: Three cases of calcinosis associated with intravenous injection of calcium gluconate (in Japanese). Nihon Keisei Geka Gakkai Zasshi 2008;28:529-533.

6 Segawa T, Yamauchi D, Amagai S, Gonochi Y, Sekino Y, Aotake Y: Calcinosis cutis after calcium gluconate extravasation. Seikei Saigai Geka 2008;51:229-300 .

7 Ono S, Ogawa R, Miyamoto D, Hyakusoku H: A case of calcinosis associated with intravenous injection of calcium gluconate (in Japanese). Hifu Rinsho 2008;50:737-739 (in Japanese).

8 Usui T, Kotani H, Hanada K, Masuda K, Suehiro M, Katoh N, Kishimoto M: Calcinosis cutis associated with intravenous injection of calcium gluconate (in Japanese). Rinsho Hifuka 2007;61:609-612.

9 Sugiyama Y, Tanaka M, Konishi N, Hashizume H: Calcinosis cutis associated with intravenous injection of calcium gluconate (in Japanese). Hifubyo Shinryo 2005;27:1273-1276.

10 Yahata Y, Shirakata Y, Hashimoto K: A case of cutaneous calcinosis following extravasation of calcium gluconate (in Japanese). Nishi Nihon Hifu 2002;64:427-429.

11 Tsukahara T, Sugai R, Nakamura H, Nagoya S: Subcutaneous calcium deposition in the neonate associated with calcium gluconate infusion (in Japanese). Seikei Geka 2001;52:202-203.

12 Sato H, Takahashi Y, Kosugiyama K, Ono A, Sageshima S, Yamaguchi J, Kumakiri M: A case of cutaneous calcinosis resulting from the extravasation of calcium gluconate (in Japanese). Obihiro Kosei Ishi 1999;2:67-71.

13 Akimoto K, Yamashita N, Kamimura T, Kawashima M: A case of calcinosis associated with intravenous injection of calcium gluconate (in Japanese). Hifu Rinsho 1990;32:1225-1228.

14 Matsuda Y, Kaneda S, Yagi M, Naito M, Naito S, Uchiyama M, Iwabuchi M: A case of cutaneous calcinosis resulting from the extravasation of calcium gluconate (in Japanese). Acta Neonatologica Japonica 1996;30:751.

15 Shimizu M, Murata K, Nogita T, Kawashima M: A case of calcinosis associated with intravenous injection of calcium gluconatev(in Japanese). Hifu Rinsho 1998;40:116-117.

The case was presented at the 76th Tokyo Division Meeting of the Japanese Dermatological Association, Tokyo, Japan. 
Watanabe et al.: Calcinosis Cutis Confined to the Dermis after Intravenous Administration of a Calcium Preparation

Table 1. Presentation of 18 cases of calcinosis cutis after administration of calcium preparations in the Japanese literature between 1990 and 2012

\begin{tabular}{|c|c|c|c|c|c|c|c|}
\hline & $\begin{array}{l}\text { Drip } \\
\text { leak }\end{array}$ & Lesion & Age & $\begin{array}{l}\text { Calcium prepa- } \\
\text { rations used }\end{array}$ & $\begin{array}{l}\text { Serum calcium/ } \\
\text { phosphate }\end{array}$ & First author & Year \\
\hline 1 & - & dermis & 61 years & CG, CC & $\rightarrow / \rightarrow$ & Our case & 2012 \\
\hline 2 & - & dermis & 7 years & $\mathrm{CG}, \mathrm{CC}$ & $\rightarrow / \rightarrow$ & Shimizu [15] & 1998 \\
\hline 3 & - & dermis & 63 years & $\mathrm{CG}$ & $\rightarrow /$ unknown & Sugiyama [9] & 2005 \\
\hline 4 & - & NB & 22 days & $\mathrm{CG}$ & $\downarrow /$ unknown & $\begin{array}{l}\text { Tsukahara } \\
{[11]}\end{array}$ & 2001 \\
\hline 5 & - & NB & 1 year & $\mathrm{CG}$ & $\rightarrow /$ unknown & Usui [8] & 2007 \\
\hline 6 & - & NB & 11 days & $\mathrm{CG}$ & $\downarrow /$ unknown & Seike [5] & 2008 \\
\hline 7 & - & NB & 2 months & $\mathrm{CG}$ & $\downarrow /$ unknown & Seike [5] & 2008 \\
\hline 8 & - & NB & 2 months & $\mathrm{CG}$ & unknown & Ono [7] & 2008 \\
\hline 9 & + & dermis & 13 days & CG & $\downarrow / \rightarrow$ & Sakai [3] & 1995 \\
\hline 10 & + & dermis & 36 years & CG & $\uparrow / \uparrow$ & Akimoto [13] & 1990 \\
\hline 11 & + & dermis & 3 years & $\mathrm{CG}$ & $\rightarrow /$ unknown & Yahata [10] & 2002 \\
\hline 12 & + & dermis & 9 years & CG & $\downarrow / \rightarrow$ & Sato [12] & 1999 \\
\hline 13 & + & dermis subcutis & 30 days & CG & $\rightarrow$ /unknown & Baba [4] & 2008 \\
\hline 14 & + & subcutis & 74 years & $\mathrm{CG}$ & $\rightarrow /$ unknown & Sugiyama [9] & 2005 \\
\hline 15 & + & NB & 20 days & CG & unknown & Matsuda [14] & 1996 \\
\hline 16 & + & NB & 11 days & $\mathrm{CG}$ & $\rightarrow / \rightarrow$ & Usui [8] & 2007 \\
\hline 17 & + & NB & 20 days & $\mathrm{CG}$ & $\downarrow /$ unknown & Seike [5] & 2008 \\
\hline 18 & + & NB & 15 days & $\mathrm{CG}$ & $\downarrow /$ unknown & Segawa [6] & 2008 \\
\hline
\end{tabular}

$\mathrm{NB}=$ Not biopsied $\mathrm{CG}=$ calcium gluconate $\mathrm{CC}$ = calcium chloride .

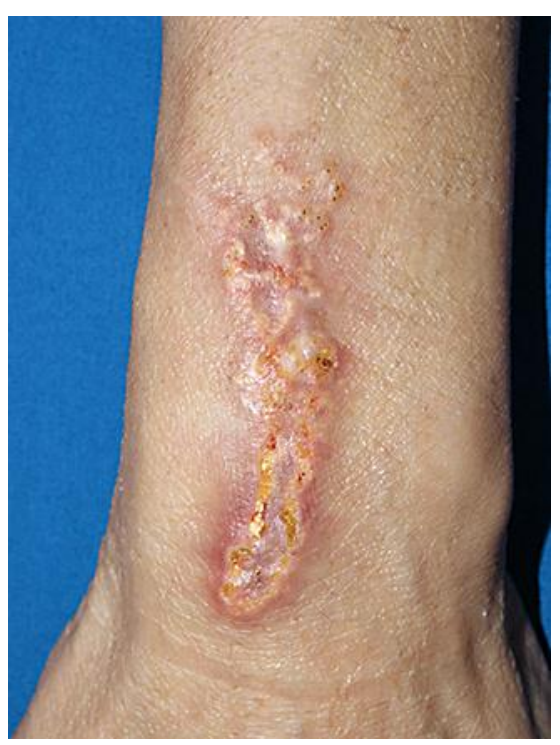

Fig. 1. Photograph of the skin lesion showing an indurated plaque measuring $13 \times 65 \mathrm{~mm}$ in size, with ulcers arranged linearly, together with yellowish-white substance. The ulcers were surrounded by reddish skin on the left forearm. 
Watanabe et al.: Calcinosis Cutis Confined to the Dermis after Intravenous Administration of a Calcium Preparation
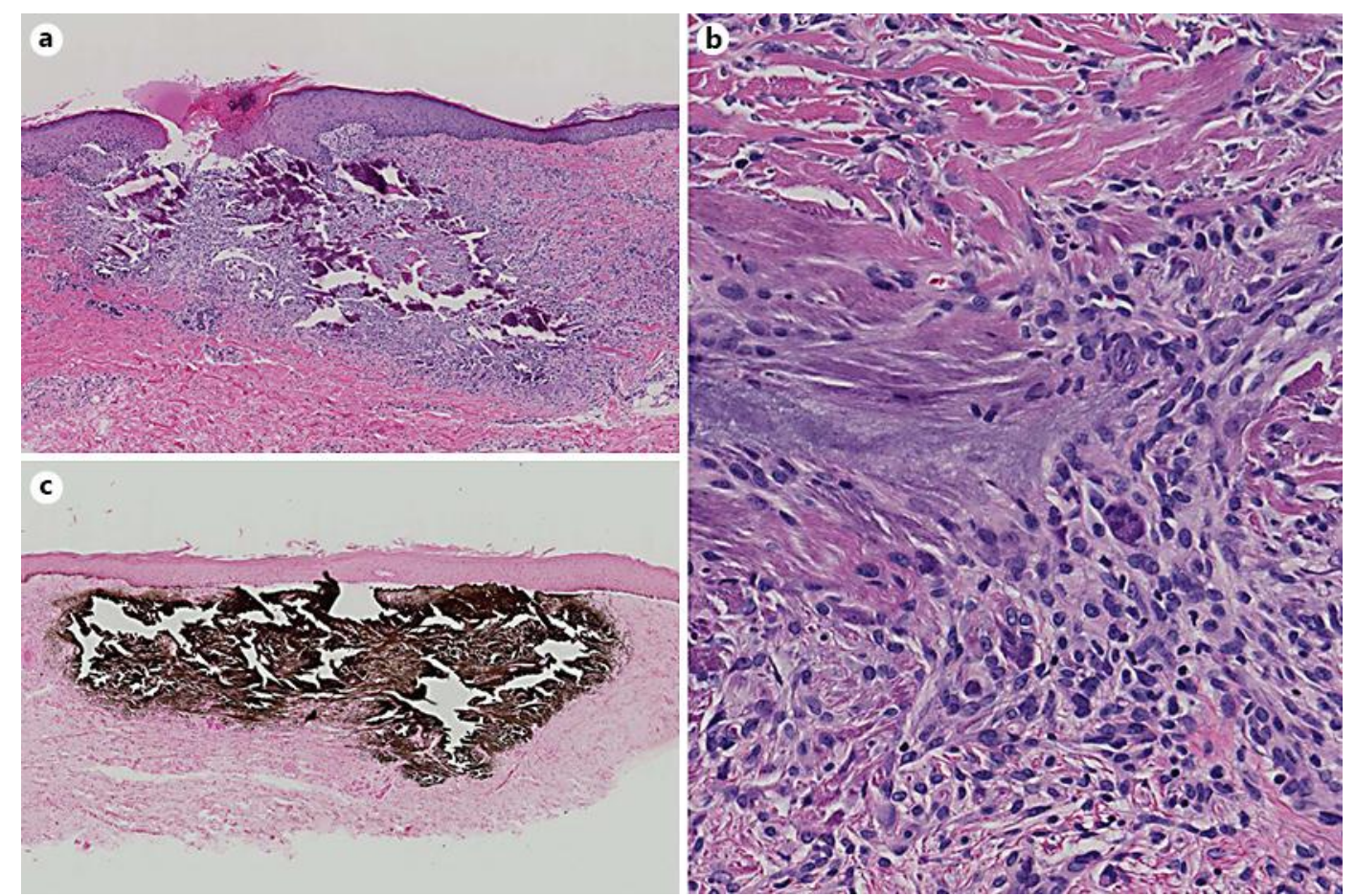

Fig. 2. a HE-stained biopsy section showing deposition of a basophilic amorphous material in the upper and middle dermis. Note also the granulomatous infiltration surrounding the amorphous substance and accumulation of collagen. b A high-power view showing histiocytic infiltrates intermingled with lymphocytes and giant cells between collagen fibers. c von Kossa staining confirmed that the amorphous substance was calcium deposition. Magnification: $\mathbf{a} \times 40 ; \mathbf{b} \times 200 ; \mathbf{c} \times 40$.

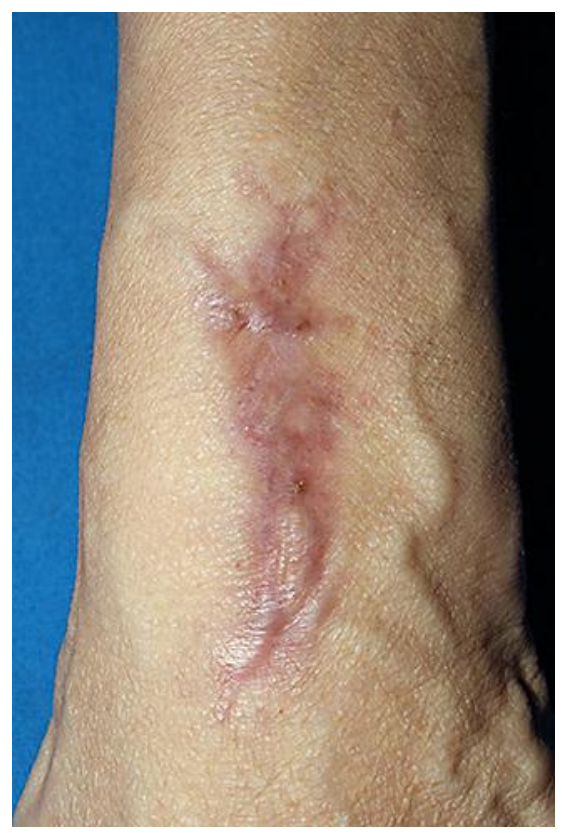

Fig. 3. Photograph of the lesion taken 2 months after treatment. Note the scar formation. 
Watanabe et al.: Calcinosis Cutis Confined to the Dermis after Intravenous Administration of a Calcium Preparation

a
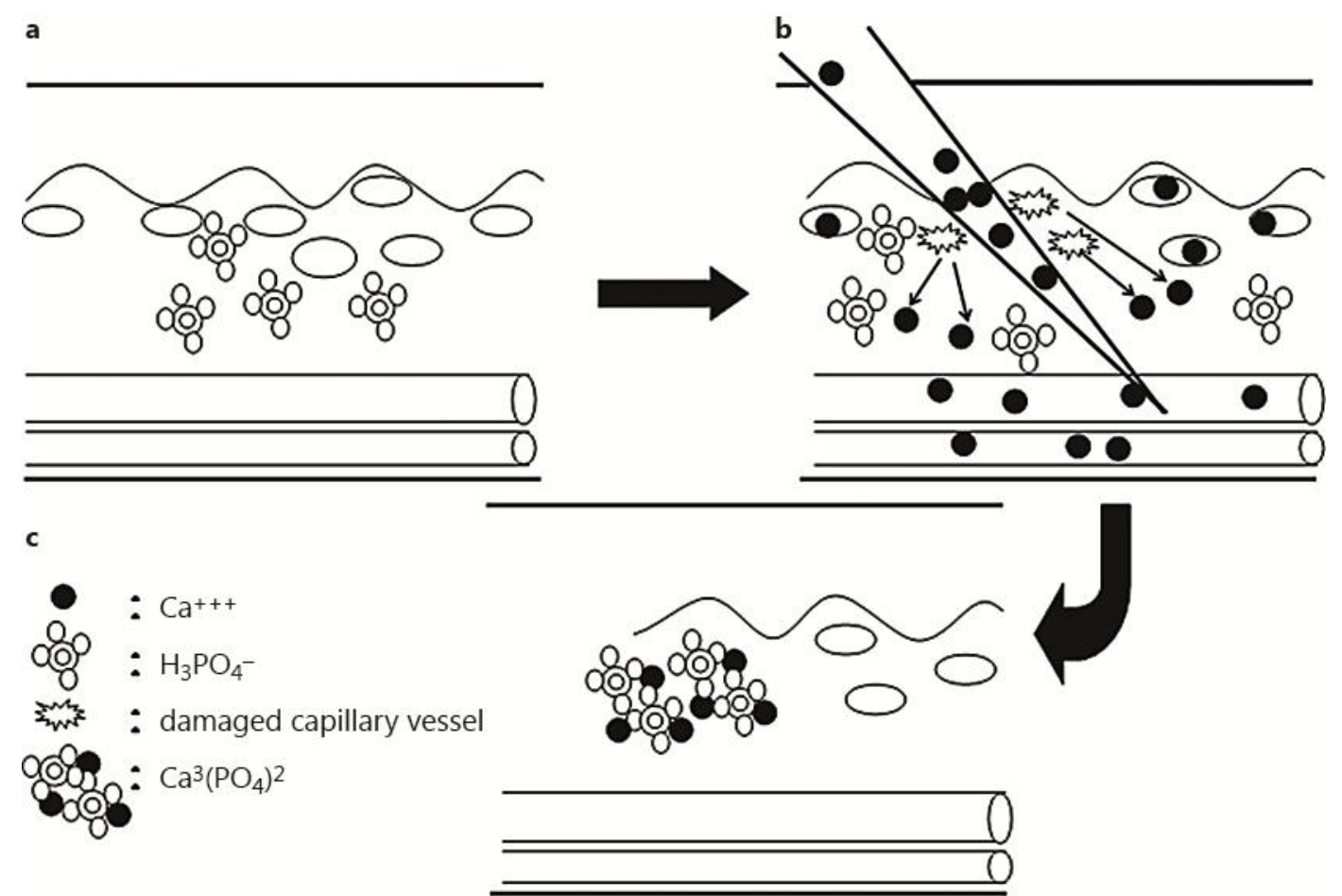

c

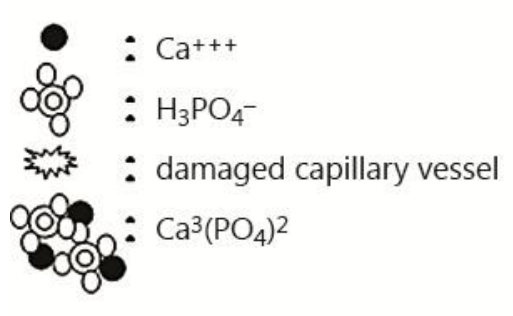

Fig. 4. Proposed mechanism of iatrogenic calcinosis cutis. a Before treatment: tissue injury induced by introduction of the needle causes capillary disruption in the dermis with calcium ion release (b). $\mathbf{c}$ The released calcium binds to phosphate in the dermis, with resultant deposition of calcium phosphate crystals in the dermis. 